\title{
Rapid production of cyclonic spray chambers for inductively coupled plasma applications using low cost 3D printer technology
}

\author{
David F. Thompson \\ School of Physical \& Geographical Sciences, Keele University, Keele, Staffordshire, UK, \\ ST5 5BG
}

\begin{abstract}
The development of low cost 3D printer technology is having a profound effect on everyday life. Over the past few years there have been many reports in the media detailing futuristic uses of this technology. Whilst the merits of these applications are clear there is an opportunity for this technology to enhance current research where a degree of fabrication is required. This work describes some initial research into the use of $3 \mathrm{D}$ printing for the fabrication of cyclonic spray chambers for inductively coupled plasma applications. The linearity, precision and detection limits obtained from the 3D printed chamber have been compared to a commercial model with largely positive results. Comparison between the performance of subsequent prints of the same spray chamber has also been carried out and has been shown to be highly reproducible. This work suggests that low-cost 3D printing techniques can be used as an inexpensive way to fabricate prototype spray chambers to accelerate the research in this area.
\end{abstract}

\section{INTRODUCTION}

With the advent of inexpensive electronics, more powerful computers and the open source movement, $3 \mathrm{D}$ additive printing has become increasing popular over the last few years ${ }^{[1,2]}$. The most common form of additive printing is that using extrusion deposition as a printing $\operatorname{method}^{[2]}$. During this process the printing material is extruded onto a flat surface that is lowered between successive layers to allow the model to be formed. This approach has been used in many applications including the production of reaction vessels that are preimpregnated with a catalyst (termed 'reactionware') ${ }^{[3-5]}$ and bioengineering projects such as the production of bone implants ${ }^{[6]}$ and tissue scaffolds ${ }^{[7]}$. Whilst it is clear that $3 \mathrm{D}$ printing technology will enable many new areas of research there are many current areas that require objects to be fabricated that could benefit from this technology. 
One area of research that has the potential to be enhanced by $3 \mathrm{D}$ printing is spray chamber design. It has long been recognised that sample transport efficiency to the plasma is a limiting factor of Inductive Coupled Plasma (ICP) based analyses ${ }^{[8-10]}$. Whilst there have been many advances in nebuliser technology to overcome this (particularly at low flow rates) the spray chambers used are largely unchanged ${ }^{[10]}$. As the most common material used in spray chamber fabrication is borosilicate glass or quartz, a significant obstacle to be overcome when undertaking this type of research is the significant funds and expertise required to fabricate a prototype without any guarantee of success. Production of such a prototype requires access to a skilled glassblower which is becoming increasing rare with the loss of traditional fabrication facilities in many universities ${ }^{[11]}$. The latter point also makes it difficult for any researcher in such a position to produce and evaluate any new designs that are presented in the literature but not yet commercially available.

The 3D printer technology described in this work has the potential to overcome these issues. This work details a relatively straight forward and inexpensive process to design and produce a cyclonic spray chamber using readily available technology and materials. To the best of our knowledge this is the first time a 3D printed spray chamber has been created for operational use. To enable a meaningful discussion, the data obtained from the 3D printed spray chamber has been compared to both an equivalent chamber that is commercially available and two subsequent prints of the same chamber. The choice of commercial spray chamber used for comparative studies was based on the instrument manufacturers' recommendation for the model of ICP used in this work.

\section{MATERIALS \& METHODS}

\section{Object design}

The 3D printed spray chambers were designed using AutoCAD 2013 software (Autodesk, Inc., San Rafael, CA). An academic (non-commercial) licence for this software is freely available from the company web site to qualifying individuals and institutions. To enable a suitable comparison, the external dimensions of the 3D printed spray chamber were based on the commercial spray chamber used as a comparison. Internal dimensions were estimated from the commercial spray chamber. Objects designed in this software were exported as a stereolithography (.stl) file allowing direct import into the printer software. 


\section{Object slicing and printing}

After importing the spray chamber file into the printer software the object must be 'sliced' to create a series of distinct 2D layers that can be printed. Object slicing and printer control was achieved using Repetier Host version 0.90c, slicing and printing parameters are shown in Table 1. This software is freely available from the printer manufacturer. The spray chambers were printed using a dual extruder Leapfrog Creatr printer (Leapfrog BV, Alphen aan den Rijn, The Netherlands). The printing medium for this type of printer is a $1.67 \mathrm{~mm}$ diameter polymer filament. The dual extruder capability of this printer allowed both a dissolvable support polymer and a structural polymer to be printed simultaneously. Polylactic Acid was used as a support material with the printing material being acrylonitrile butadiene styrene (ABS), both of these materials were purchased directly from the printer manufacturer.

After printing the support material is removed by sonicating the spray chamber in $1 \mathrm{M}$ sodium hydroxide (Sigma-Aldrich, Poole, Dorset) at $60^{\circ} \mathrm{C}$ for $3-4$ hours. The spray chamber was produced in parts to allow a complete inspection prior to its use on the instrument (see Figure 1). The parts of the spray chamber were bonded together using epoxy resin.

\section{Comparison with commercial spray chamber}

All comparisons described in this work were carried out using a Varian Vista MPX ICP-OES (Agilent Technologies, Santa Clara, CA). The commercial cyclonic spray chamber used for comparative studies (\#98301) was produced by Glass Expansion (Pocasset, MA). Operating parameters of this instrument are listed in Table 2. During all comparisons the following elements were monitored: $\mathrm{Ag}, \mathrm{Al}, \mathrm{B}, \mathrm{Ba}, \mathrm{Bi}, \mathrm{Ca}, \mathrm{Cd}, \mathrm{Co}, \mathrm{Cr}, \mathrm{Cu}, \mathrm{Fe}, \mathrm{Ga}, \mathrm{Ir}, \mathrm{Li}, \mathrm{Mg}, \mathrm{Mn}, \mathrm{Ni}$, $\mathrm{Pb}, \mathrm{Sr}, \mathrm{Ti}, \mathrm{Zn}$. These were obtained from a $1000 \mathrm{ug} / \mathrm{mL}$ multi-element plasma standard (\#42885) purchased from Alfa Aesar (Heysham, Lancashire). Standards with concentrations between 2 and $10 \mu \mathrm{g} / \mathrm{mL}$ were prepared using ultrapure water (18 $\mathrm{M} \Omega$ ) produced in-house using an ELGA Option-Q System (Veolia Water, Saint Maurice, France). The wash solution used throughout the analysis was $5 \%$ nitric acid; this was purchased from Fisher Scientific (Loughborough, UK) in a concentrated form (70\% analytical grade) and diluted with ultrapure water. Triplicate analysis of the aforementioned standards allowed the linearity and precision of the analysis to be calculated. The limit of detection for each element was calculated by adding 3 standard deviations to the average signal obtained from the analysis of 20 blank samples. Data obtained from the conventional cyclonic spray chamber and the 3D printed version were collected on the same day using the same standards. 


\section{D printed spray chamber reproducibility}

Further analysis was carried out to assess the reproducibility between 3 spray chambers that had been printed to the same design. The same standards (as mentioned above) were used in this evaluation.

\section{RESULTS \& DISCUSSION}

An example of the spray chambers produced using the 3D printer can be seen in Figure 1. The initial analyses focused on the performance of the 3D printed spray chambers compared to a commercial product. The data relating to the linearity, precision and detection limit can been seen in Table 3. The average linearity, as expressed by the coefficient of determination $\left(\mathrm{R}^{2}\right)$, is identical for both the commercial and 3D printed spray chambers, with a value of 0.993. The linearity ranged from 0.978 to 0.999 for the commercial spray chamber and 0.981 to 0.999 for the 3D printed spray chamber. Triplicate analysis allowed the imprecision in the data from both spray chambers to be determined. For the commercial spray chamber the imprecision ranged from 0.15 to $8.0 \%$ with an average value of $1.1 \%$ over all of the calibration standards. For the 3D printed spray chamber the imprecision ranged from 0.1 to $8.3 \%$ with an average value of $1.3 \%$. Analysis of the detection limit data showed there was a trend for the 3D printed spray chamber to have a higher detection limit, for a given element, than the commercially available chamber. The increase in the detection limit ranged from 15.8 to $104.9 \%$ of the value obtained from the commercially available chamber, the average increase was $54.5 \%$.

These results highlight the similarity in performance between the $3 \mathrm{D}$ printed spray chamber and its commercial counterpart. It is likely that the increase in the detection limits observed when using the $3 \mathrm{D}$ printed spray chamber is due to physical differences in the design of two spray chambers. In particular the angle of the chamfer at the base of the tube that transfers the aerosol from the spray chamber to the ICP, this was difficult to replicate without causing irreparable damage the original spray chamber. The effect on washout time between the two spray chambers could also be a factor effecting this observation. However, analysis of the data obtained from the blanks does not show any trend suggesting a reduction in signal over the course of this analysis.

If this manufacturing approach is to be practically feasible it is important to be able to produce multiple spray chambers, from the same design, that have similar performance 
characteristics. To this end two additional spray chambers were printed using the same CAD files and construction methodology. Analysis of the same standard solutions as the previous study gave an average imprecision of $6.6 \%$ over a range from 0.5 to $18.0 \%$. These measurements were all carried out on the same day but the plasma was extinguished as the chambers were changed.

The aforementioned performance characteristics of the 3D printed spray chambers show that they are able to produce data that are comparable in quality and signal intensity to that of a commercial model. Additional analysis indicates that subsequent prints of the spray chambers give comparable results. These characteristics permit the use of these techniques to produce low-cost prototype chambers that can be easily modified. The typical material cost per print is less than $\$ 5$ with the printer used in this work being priced around $\$ 2000$. The development of the printer technology since the purchase of this model now means a printer capable of producing these spray chambers is now available for around $\$ 900$. This low-cost production has the potential to accelerate the development of new spray chambers as the production time is very short and there is little financial risk associated with a 'failed' model. Additionally, with the printer files being easy to distribute, anyone with a 3D printer could produce their own print to verify its performance on any instrument. An additional advantage of this production method is the ability, for somebody who does not have access to traditional fabrication methods, to replicate new spray chambers that have been highlighted in the literature but are not yet commercially available. This would allow developments made in this area to be utilised by the community as a whole in a short space of time from publication. An example of this is the range of dual nebuliser (hydride forming) spray chambers that have been reported ${ }^{[12-14]}$.

The disadvantages of the described methodologies include the limited number of polymers that are currently available as printing filament; those that are available have limited chemical resistance. ABS is resistant to aqueous acids and alkalis and concentrated hydrochloric acid. It is not recommended that you use a concentration of nitric acid over $50 \%$ or use glacial acetic or formic acid ${ }^{[15]}$. This more limited chemical resistance would cause little problem for conventional ICP analyses but it is less than that offered by a quartz or borosilicate chamber so it is worth highlighting. From a practical point of view the spray chambers produced using these methods are opaque so it is not possible to observe the nebulised sample stream in the chamber. This could be addressed by the addition of viewing windows into any design where this would be a significant issue. Additionally, the layered approach used during printing 
makes the surface of chambers relatively rough, this type of surface is likely to be significantly wettable therefore facilitating the adherence of sample droplets to the inner surfaces $^{[16]}$. This would increase the sample washout time and increase carryover. It is possible this effect could be negated by either mechanically or chemically smoothing the inner surfaces or by the application of a hydrophobic coating such as that developed by Mulazim et al ${ }^{[17]}$.

\section{CONCLUSIONS}

This research has demonstrated the potential use of 3D additive printing techniques for the rapid fabrication of cyclonic spray chambers for ICP based techniques. The reproducibility demonstrated by the $3 \mathrm{D}$ printed spray chamber is comparable to that of a commercial version and inter-spray chamber reproducibility has been demonstrated. Issues with the elevated detection limits and the effect the layer production require further investigation.

This work opens the possibility of using the described techniques to develop novel spray chambers that can be tailored to specific applications and flow rates. With the reproducibility demonstrated these spray chambers could be used 'as is' or as a prototype for fabrication from more conventional materials. Whilst this research is in its infancy there is a clear potential for $3 \mathrm{D}$ printing to have a positive impact on the development of equipment for analytical instrumentation. 


\section{REFERENCES}

[1] M. Catarina, The rise of personal fabrication, Proceedings of the 8th ACM conference on Creativity and cognition 2011.

[2] B. Berman, 3-D printing: The new industrial revolution, Business Horizons 2012, 55, 155.

[3] P. J. Kitson, M. H. Rosnes, V. Sans, V. Dragone, L. Cronin, Configurable 3D-Printed millifluidic and microfluidic 'lab on a chip' reactionware devices, Lab on a Chip 2012, $12,3267$.

[4] P. J. Kitson, M. D. Symes, V. Dragone, L. Cronin, Combining 3D printing and liquid handling to produce user-friendly reactionware for chemical synthesis and purification, Chemical Science 2013, 4, 3099.

[5] M. D. Symes, P. J. Kitson, J. Yan, C. J. Richmond, G. J. T. Cooper, R. W. Bowman, T. Vilbrandt, L. Cronin, Integrated 3D-printed reactionware for chemical synthesis and analysis, Nat Chem 2012, 4, 349.

[6] C. Bergmann, M. Lindner, W. Zhang, K. Koczur, A. Kirsten, R. Telle, H. Fischer, 3D printing of bone substitute implants using calcium phosphate and bioactive glasses, Journal of the European Ceramic Society 2010, 30, 2563.

[7] S. M. Peltola, F. P. W. Melchels, D. W. Grijpma, M. Kellomaki, A review of rapid prototyping techniques for tissue engineering purposes, Annals of Medicine 2008, 40, 268.

[8] R. B. A. Browner, Sample Introduction: The Achilles' Heel of Atomic Spectroscopy, Analytical Chemistry 1984, 56, 786.

[9] J. W. Olesik, Peer Reviewed: Fundamental Research in ICP-OES and ICP-MS, Analytical Chemistry 1996, 68, 469A.

[10] J. L. Todoli, J. M. Mermet, Sample introduction systems for the analysis of liquid microsamples by ICP-AES and ICP-MS, Spectrochimica Acta Part B: Atomic Spectroscopy 2006, 61, 239.

[11] R. Petkewich, An Essential Craft, Chemical \& Engineering News 2006, 84, 9.

[12] A. Asfaw, G. Wibetoe, Dual mode sample introduction for multi-element determination by ICP-MS: the optimization and use of a method based on simultaneous introduction of vapor formed by $\mathrm{NaBH}_{4}$ reaction and aerosol from the nebulizer, Journal of Analytical Atomic Spectrometry 2006, 21, 1027. 
[13] L. R. Gomez, G. D. Marquez, J. R. Chirinos, Dual nebulizer sample introduction system for simultaneous determination of volatile elemental hydrides and other elements, Analytical and Bioanalytical Chemistry 2006, 386, 188.

[14] D. Maldonado, J. Chirinos, Z. Benzo, C. Gomez, E. Marcano, Analytical evaluation of a dual micronebulizer sample introduction system for inductively coupled plasma spectrometry, Journal of Analytical Atomic Spectrometry 2006, 21, 743.

[15] Cole-Palmer, Chemical Compatibility Database, available at: http://www.coleparmer.co.uk/Chemical-Resistance.

[16] P. Roach, N. J. Shirtcliffe, M. I. Newton, Progess in superhydrophobic surface development, Soft Matter 2008, 4, 224.

[17] Y. Mülazim, E. Çakmakçi, M. V. Kahraman, Properties of Thiol-ene Photocurable Highly Hydrophobic and Oleophobic Nanocomposite Coatings on ABS and HIPS Substrates, Advances in Polymer Technology 2013, 32, E416. 


\section{FIGURES \& TABLES}

Figure 1 - An overview of the production of the 3D printed cyclonic spray chamber. Top The constituent parts of the spray chamber after printing, the blue material (ABS) is the structural elements of the chamber, the white material (PLA) is a dissolvable support to enable the conical shaped top of the chamber to be printed (the chamber is shown upside down on the print bed). Middle - The assembled spray chamber in position on the instrument. Bottom - A cross-sectional representation of the 3D-printed spray chamber in position on the instrument.

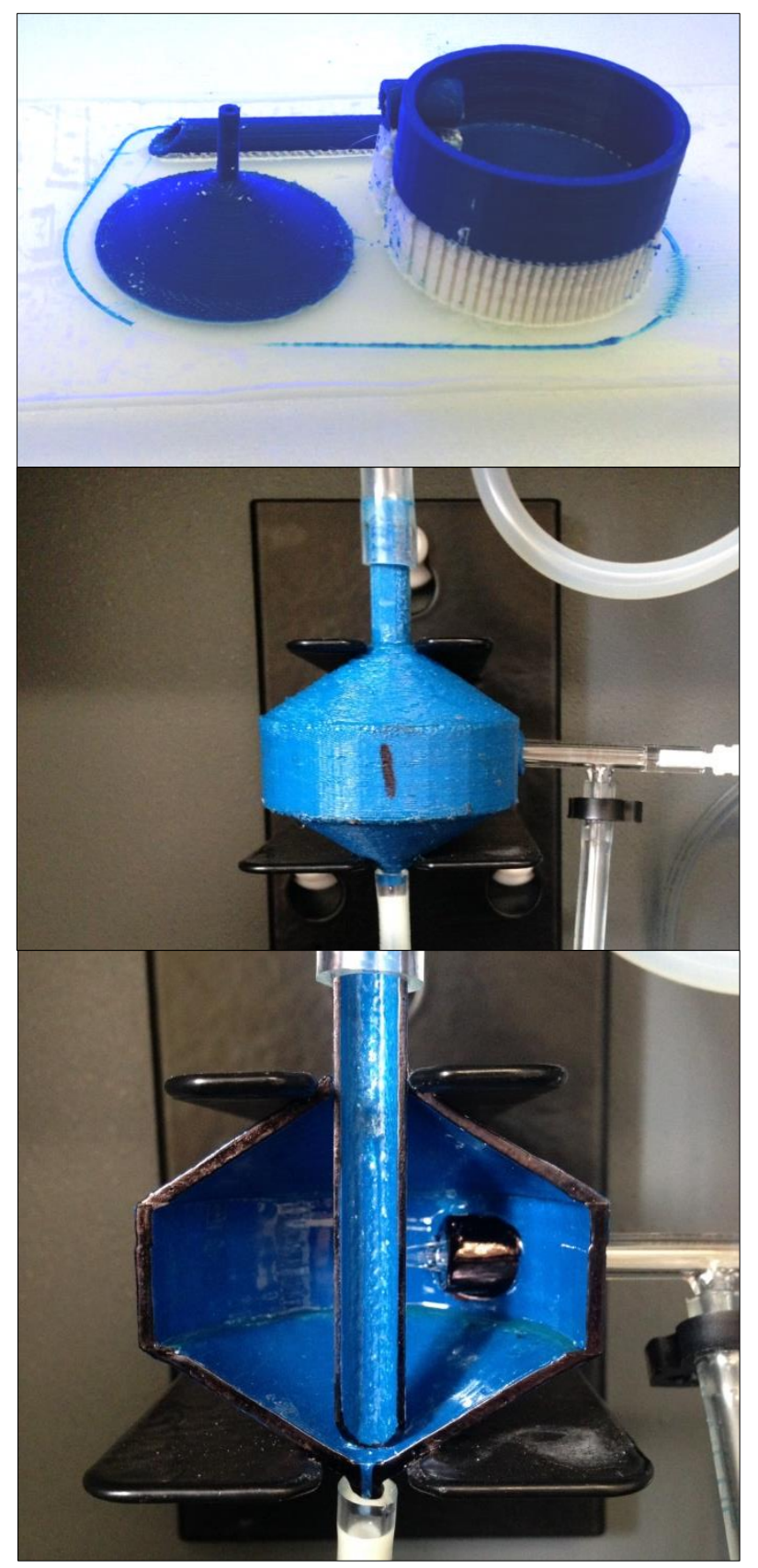


Table 1 - Slicing and printing parameters of the Leapfrog Creatr 3D printer

\begin{tabular}{|c|c|}
\hline \multicolumn{2}{|c|}{ Printer Configuration } \\
\hline $\begin{array}{c}\text { Structural Printing } \\
\text { Material }\end{array}$ & $\begin{array}{c}\text { Acrylonitrile } \\
\text { butadiene styrene } \\
\text { (ABS) }\end{array}$ \\
\hline $\begin{array}{c}\text { Support Printing } \\
\text { Material }\end{array}$ & $\begin{array}{c}\text { Polylactic Acid } \\
\text { (PLA) }\end{array}$ \\
\hline $\begin{array}{c}\text { Filament diameter } \\
\text { (mm) }\end{array}$ & 1.75 \\
\hline $\begin{array}{c}\text { ABS Extruder } \\
\text { Temperature }\left({ }^{\circ} \mathrm{C}\right)\end{array}$ & 220 \\
\hline $\begin{array}{c}\text { PLA Extruder } \\
\text { Temperature }\left({ }^{\circ} \mathrm{C}\right)\end{array}$ & 195 \\
\hline $\begin{array}{c}\text { Print Bed } \\
\text { Temperature }\left({ }^{\circ} \mathrm{C}\right)\end{array}$ & 80 \\
\hline Layer Height $(\mathrm{mm})$ & 0.2 \\
\hline Fill density $(\%)$ & 40 \\
\hline $\begin{array}{c}\text { ABS Print Speed } \\
(\mathrm{mm} / \mathrm{s})\end{array}$ & 40 \\
\hline $\begin{array}{c}\text { PLA Print Speed } \\
\text { (mm/s) }\end{array}$ & 50 \\
\hline
\end{tabular}


Table 2 - Operating conditions of the Varian Vista MPX ICP-OES

\begin{tabular}{|c|c|}
\hline \multicolumn{2}{|c|}{ Instrument Conditions } \\
\hline Plasma Power $(\mathrm{kW})$ & 1.0 \\
\hline $\begin{array}{c}\text { Plasma Gas Flow } \\
(\mathrm{L} / \mathrm{min})\end{array}$ & 15.0 \\
\hline $\begin{array}{c}\text { Aux Gas Flow } \\
(\mathrm{L} / \mathrm{min})\end{array}$ & 1.5 \\
\hline $\begin{array}{c}\text { Nebuliser Gas Flow } \\
(\mathrm{L} / \mathrm{min})\end{array}$ & 0.75 \\
\hline Viewing Height $(\mathrm{mm})$ & 10 \\
\hline Replicates & 3 \\
\hline $\begin{array}{l}\text { Replicate read time } \\
\text { (s) }\end{array}$ & 5 \\
\hline \multicolumn{2}{|c|}{ Monitored Wavelengths (nm) } \\
\hline $\mathrm{Ag}$ & 328.068 \\
\hline $\mathrm{Al}$ & 396.152 \\
\hline B & 249.772 \\
\hline $\mathrm{Ba}$ & 455.403 \\
\hline $\mathrm{Bi}$ & 223.061 \\
\hline $\mathrm{Ca}$ & 396.847 \\
\hline $\mathrm{Cd}$ & 514.437 \\
\hline Co & 238.892 \\
\hline $\mathrm{Cr}$ & 267.716 \\
\hline $\mathrm{Cu}$ & 327.395 \\
\hline $\mathrm{Fe}$ & 238.204 \\
\hline $\mathrm{Ga}$ & 294.363 \\
\hline Ir & 224.268 \\
\hline $\mathrm{Li}$ & 670.783 \\
\hline $\mathrm{Mg}$ & 279.553 \\
\hline $\mathrm{Mn}$ & 257.610 \\
\hline $\mathrm{Ni}$ & 231.604 \\
\hline $\mathrm{Pb}$ & 220.353 \\
\hline $\mathrm{Sr}$ & 407.771 \\
\hline $\mathrm{Tl}$ & 190.794 \\
\hline $\mathrm{Zn}$ & 213.857 \\
\hline
\end{tabular}


Table 3 - Comparison between the performance characteristics of the 3D printed spray chamber and a commercial counterpart.



